\title{
Research on the Application of Sports Games in College Basketball Classroom Teaching
}

\author{
Fei Liu \\ University of Electronic Science and Technology of China, Chengdu, Sichuan, 611731
}

Keywords: Sports Games, College Basketball Teaching, Application Study.

\begin{abstract}
With the continuous reform of China's education system, the teaching method of sports games began to apply to the physical education classroom, the sports game has a certain interest, can improve the interest of students to learn sports. The college basketball classroom teaching mode is too single, the students through the dribble, pitching, picking up, easy to make students tired, and then lost the interest in learning basketball. But in the college basketball classroom using sports game method, can improve the initiative of students to learn, so as to improve the quality of teaching.
\end{abstract}

\section{Introduction}

Basketball is a popular sports project, college students through basketball training, not only can keep fit, but also can release the students' learning pressure, so that students physical and mental health development. With the continuous development of China's basketball career, colleges and universities began to pay attention to basketball courses, and basketball teaching put forward higher requirements. In the basketball classroom teaching the introduction of sports game teaching methods, not only can improve student participation, but also can be active classroom atmosphere, so as to improve students' interest in basketball.

\section{The Present Situation of Basketball Teaching in Colleges and Universities}

Basketball has a long history, has an important position in college sports, basketball can not only exercise the students' body, but also can basketball sports as the carrier, the students moral education, to the students to establish a good moral education. At present, in the process of college basketball teaching, although students like basketball, but the lack of basketball course learning, mainly because the teacher uses the traditional teaching philosophy, in the teaching mode is not innovation, is still a ball, dribble, Over time, repeated practice, resulting in students lost their interest in learning. In the whole teaching process are mostly one-way between teachers and students to pass, classroom atmosphere depression, resulting in students lack of learning initiative, some basketball enthusiasts have gradually lost the confidence of learning basketball [1], resulting in the expected Teaching objectives, classroom teaching quality decline, the enthusiasm of students to learn is not high.

\section{The concept and characteristics of sports games}

According to the survey of scholars, the game is a kind of recreational activity that people get in the process of development. Some experts think that the game is evolving from the game. Through the continuous development and reform of the people, Now the sports game, for college physical education has an important role. Sports game is an important part of the teacher's physical education teaching, mainly based on the basic movements of the active body, according to the teaching content for purposeful, creative physical training or activities to change the traditional boring sports classroom atmosphere, to create a student Relaxed, happy sports classroom. Sports games in colleges and universities is mainly to allow students to physical and mental health development, so 
that students like sports, reduce the pressure on learning, sports games is to assist teachers to complete the content of physical education, is a modern college physical education On the indispensable game method.

Sports game is a branch of the game, so it has its own interesting, competitive, entertainment and other aspects of the characteristics. Sports games are for students to compete in the joy of the classroom atmosphere, so that students in the competition to experience the fun of competition, improve the excitement of the central nervous system. Sports teacher in the classroom teaching the introduction of sports games, students can reduce the boring feeling of physical education, which in line with the psychological needs of college students, so the sports game in the classroom by the students love. In addition, the content of sports games is very broad, any sport can become the content of sports games, sports equipment for no restrictions, to facilitate the teacher to carry out physical education [2]. As the sports game contains the competition factors, can effectively stimulate the enthusiasm and morale of students, and the form of lively, by the students love, is conducive to physical education teachers in the classroom teaching, sports games can develop students' physical, intellectual, Promote the overall development of students. But also through sports games to develop students' moral education ideas, therefore, sports games for sports teaching have a positive meaning.

\section{The Effect of Sports Games on Basketball Teaching}

In the basketball classroom teaching, the sports teacher can use the method of sports games to introduce the knowledge of basketball knowledge, so that students in the game to deepen the understanding of basketball, in order to master the basketball movement skills, will be better than the teacher's boring explanation The But it should be noted that the sports game to be consistent with the spirit and rules of basketball, students gradually deepen the understanding of the game but also to strengthen the understanding of basketball, thereby improving the quality of basketball classroom teaching. In the basketball classroom, the introduction of sports games, teachers to guide students and interaction, to strengthen the emotional exchanges between teachers and students, but also to meet the curiosity of students for basketball and curiosity, so that students for the rules of basketball And features have a deep understanding.

In the basketball classroom using sports games, can improve the interest of students for basketball, so that students of the cerebral cortex nerve center with excitement, thereby enhancing the students for the basketball movement to master. For example, in the students about basketball dribbling, you can use the "dribbling relay" game for students to participate in them to improve students learning basketball initiative, so that students pay more attention, concentrate on dribbling, improved The strength of basketball practice. Compared with the traditional grouping exercises, sports games have a certain degree of competition, to stimulate students 'desire to win, so threw into the dribble, the quality of students' practice has been significantly improved, effectively improve the basketball classroom teaching effectiveness.

In the traditional basketball training, the practice form is too single, repeat, it is easy to make students feel tired or tired of feeling, resulting in student practice interest is not high, there is lazy phenomenon, students want to be able to quickly practice, To the expected teaching requirements, leading to the decline in the quality of basketball teaching. For example, in the practice of passing the ball, the traditional training method is to make a group of two students in a group or in the side to run the ball practice, students can practice several times, repeated practice will cause more students Tired of the mood. However, if the traditional method based on the addition of sports games, through the form of the game to pass the ball practice, not only to mobilize the enthusiasm of students to participate, but also allow students to do the game in the process of mastering the action of the ball. Sports teacher in the basketball classroom using sports game method, will improve the students learning basketball interest, because the game practice method for the students is relatively new, with a certain degree of competition, can effectively improve the initiative of students to practice, so that students In the joy, relaxed atmosphere to complete the exercise, forget the exercise of fatigue, improve the density and intensity of basketball exercises [3], so that students 
achieve the purpose of exercise, so that the physical and mental health of students to develop.

Sports teacher in the basketball classroom teaching process, we should pay attention to play the status of students as the main body, the students in the classroom teaching an important position to give students more free space, so that students free team to participate in sports games, improve students The enthusiasm of the. For example, in the basketball teaching competition, to prevent students from some bad habits, to cultivate the team spirit of the students, to students to establish a new concept of basketball, in the offense to prohibit students dribbling. So, the teacher can let the students through running, cover the way to create the opportunity to catch the ball, because the level of each student is not much difference between the students in order to win will rely on teamwork in the form of defense, according to the opponent's Characteristics and the actual situation to develop the game tactics, so that students recognize the importance of teamwork [4], can effectively develop the team spirit of students, interpersonal skills, improve students 'moral education ideas, and thus improve the students' comprehensive ability.

In the basketball classroom, the use of sports games to cultivate students honest, perseverance, mutual cooperation and other good quality, good psychological quality of basketball practice has an important role in enabling students to play the normal skills. With the rapid development of society, students face more and more employment pressure, good psychological quality for college students more and more important, students need to have a good psychological quality to adapt to social life. Sports games in the basketball classroom, to develop students' innovative thinking ability, students have an optimistic attitude to face the pressure of learning and life, so that students with full enthusiasm and state to face life. In addition, the sports game can also carry out ideological and moral education of students, so that the healthy development of students' physical and mental health, and thus improve the efficiency of basketball classroom teaching.

\section{The Application of Sports Games in Basketball Teaching}

In the college basketball classroom, preparation activities have an important role, if the student's preparatory activities failed, can not enter the next part of basketball learning. In the course of basketball teaching, the teacher's preparation activities are mainly jogging, positioning exercises, if repeated practice will make students boring, no learning interest, classroom atmosphere will be more depressed, dull, but in basketball classroom teaching using sports games Methods, to join the development of the ball game, such as the ball, etc, the development of flexible quality of the game, such as the ball hit each other [6]. Through this form of the game can improve students' interest in basketball, enthusiasm for basketball learning, for the next part of the teaching content to make a good bedding.

With the continuous reform of China's education system, emphasis on students in the teaching process of the dominant position, so in the college basketball classroom teachers to students, so that students actively participate in basketball practice. Students need to master the skills of basketball, take some time, the formation of action skills is a complex process, students have a good physical fitness as a basis in order to master the action skills. In the basketball classroom using sports games, can effectively improve the classroom atmosphere, so that boring technical practice becomes lively and interesting, and thus improve the students learning basketball initiative. In the case of change is to strengthen the basketball skills, to enable students to master sports skills. For example, in the basketball dribbling, the sports teacher can use dribbling relay and other games to improve student interest; in passing teaching, the use of passing relay, passing count and other games; in the pitching process, the use of shooting and other games , To mobilize the enthusiasm of students, so that students actively participate in teaching practice. In the college basketball classroom to introduce sports games, can make basketball practice become interesting, competitive, so that students threw himself into the basketball training, so as to better grasp the basketball skills.

In the basketball classroom, the use of monotonous training methods will make students training tedious, affecting the effectiveness of basketball classroom teaching, so the teacher according to the physical quality of each student to carry out effective training, even if the same training content, teachers have to change the training And methods to improve the enthusiasm of student training. 
The use of sports games in the basketball classroom to stimulate students' interest in training, so that students in a relaxed atmosphere to master the action skills, and then improve the training effect, in the training can use the following games to improve student training interest. For example, the development of leg strength of the times train, frog jump relay, etc .; the development of upper limb strength of the push car; the development of sensitive quality hunters playing rabbits and other games [7], the teacher can strengthen the physical quality of these students practice, so that The development of students' physical and mental health.

The use of sports games in the basketball classroom, but also effectively eliminates the physical fatigue of the students, making the body transition from a state of tension to a stable state. Among them, some small load of the game activities can make the excitement of the movement gradually deepened to the central nervous system, so as to promote the recovery of the students body. In the relaxation activities, mainly in order to relax the fatigue of students, excited, so the game content to be relaxed, lively, so that students have been relaxed body and mind.

\section{Conclusion}

Sports games in the college basketball classroom has an important role, it can improve students' interest in learning basketball, enrich the teaching content. Sports teacher in the basketball teaching process, to the sports game as an auxiliary means of training, the teacher can be based on the teaching content to create some interesting games to mobilize students to participate in basketball practice enthusiasm.

\section{References}

[1] Huang Kai, from Jianqiu. On the sports game in college basketball teaching application [J]. Sports, 2016, (07): $87+98$.

[2] Wang Tong, Ma Wenqing. Sports games in college basketball classroom application research [J]. China School Physical Education (Higher Education), 2016,3 (01): 79-82.

[3] Wang Guangming. On the sports game in college basketball teaching application [J]. Science and Technology Information, 2010, (12): 269.

[4] Yin Lili. Sports games in college basketball teaching application [J]. Sports World (Academic Edition), 2010, (10): 22-23.

[5] Zhang Mingde. Basketball game in college basketball sports teaching application [J]. Contemporary sports science and technology, 2017,7 (06): $109+111$.

[6] Dong Xuejiao. Sports game teaching method in college physical education classroom application research [J]. Contemporary sports science and technology, 2014,4 (06): 108-109.

[7] Wang Yong, Zhang Tianliang. Basketball teaching in the sports game application [J]. Sports World (Academic Edition), 2009, (02): 44-45. 